\title{
Erratum zu: Grundwassermonitoring im Zusammenhang mit der hydraulischen Stimulation einer Erdölbohrung
}

\author{
Carola Bönsch $^{1} \cdot$ Swantje Basan $^{1}$
}

Online publiziert: 14. März 2016

(C) Springer-Verlag Berlin Heidelberg 2016

Erratum zu: Grundwasser - Zeitschrift

der Fachsektion Hydrogeologie

DOI 10.1007/s00767-015-0314-8

Im ursprünglichen Beitrag war in den Überschriften von Tab. 2b und Tab. 2d jeweils ein Fehler, der nun korrigiert wurde. Der Vollständigkeit halber finden Sie die beiden Tabellen mit ihren korrekten Überschriften auf den nächsten Seiten.

Weiterhin wurden die Verweise auf die Tab. $2 b$ bis d im Text angepasst.

Die Onlineversion des Originalartikels finden Sie unter doi:10.1007/s00767-015-0314-8.

Carola Bönsch

carola.boensch@geo-cb.de

UmweltPlan Stralsund GmbH, Tribseer Damm 2, 18437

Stralsund, Deutschland 


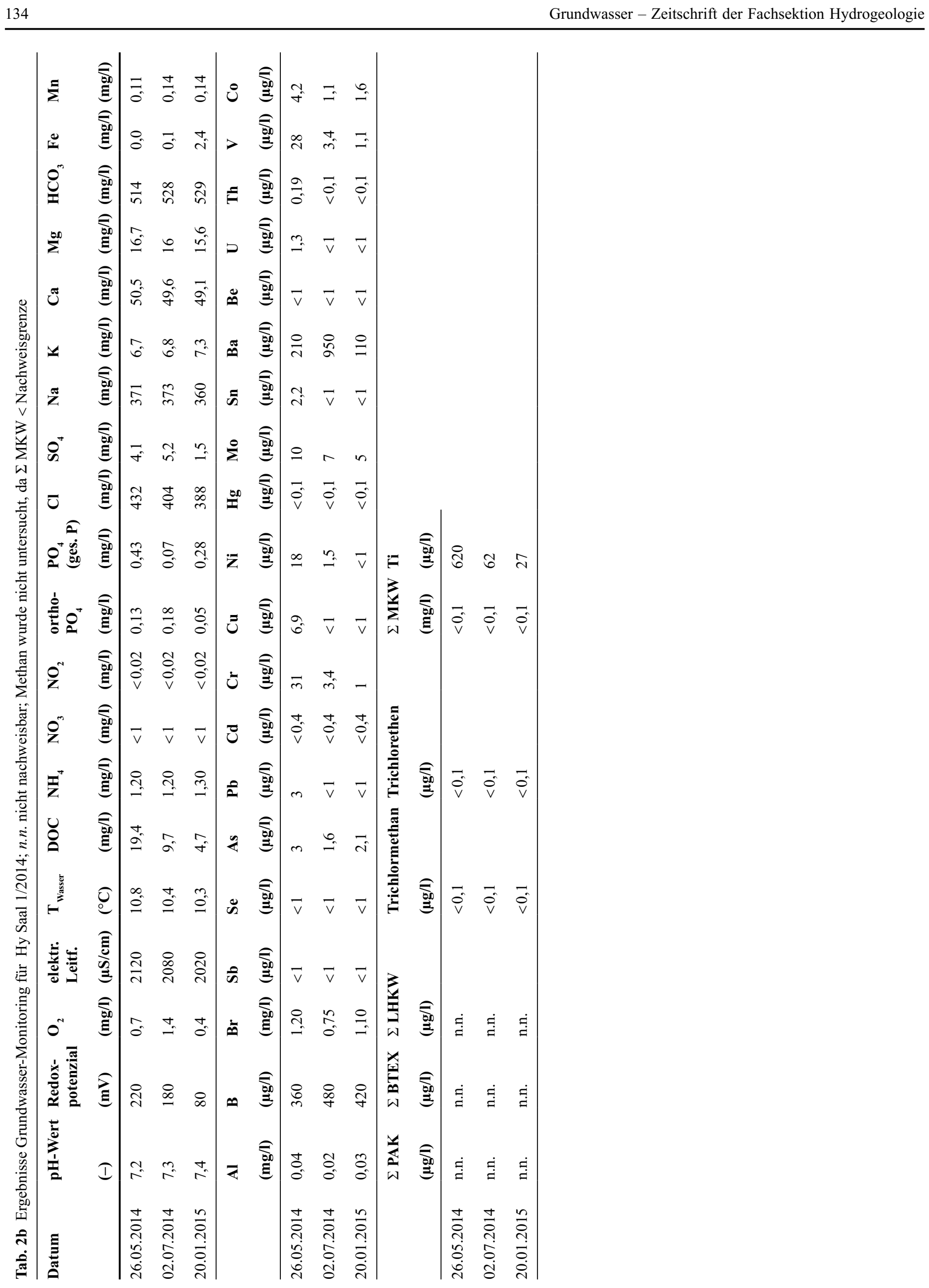

Springer 
Grundwasser - Zeitschrift der Fachsektion Hydrogeologie

135

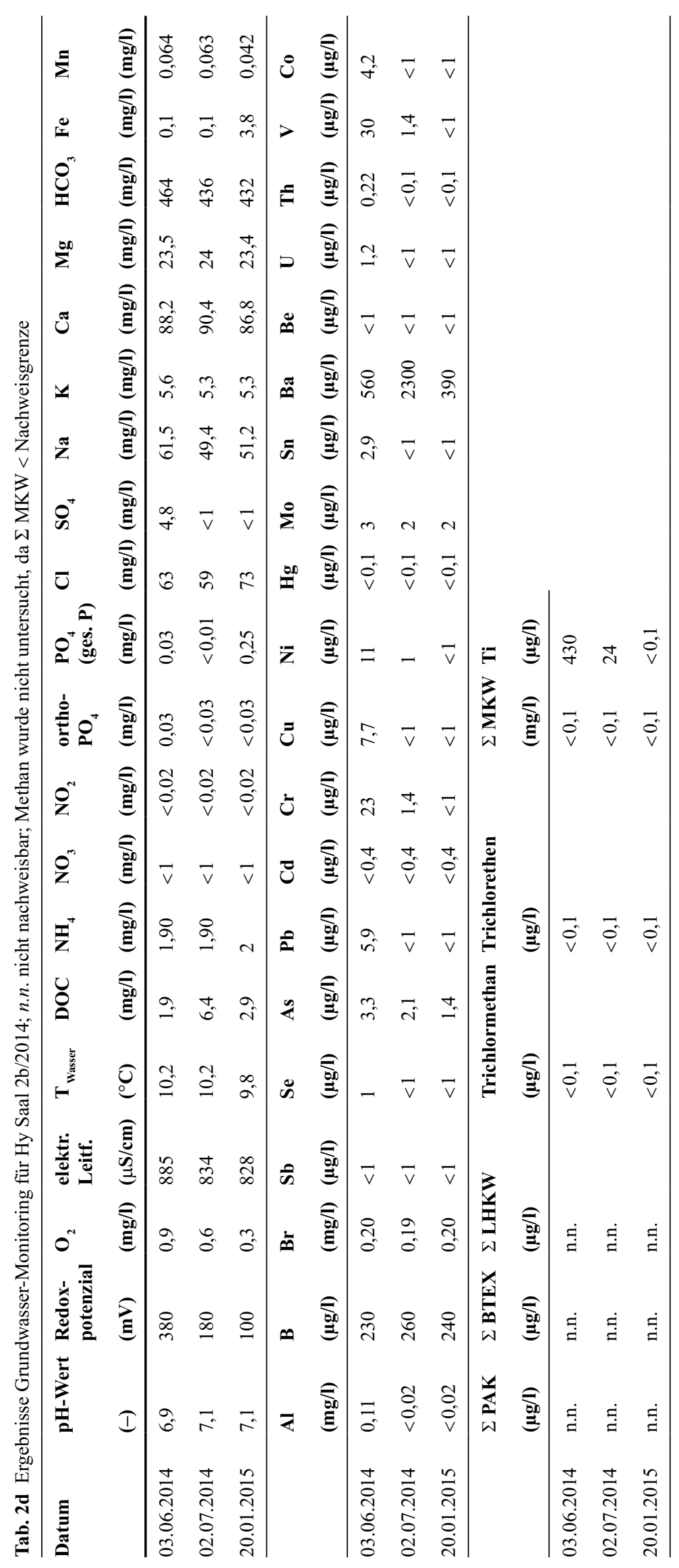

望 Springer 